Egyptian Journal of Aquatic Biology \& Fisheries

Zoology Department, Faculty of Science,

Ain Shams University, Cairo, Egypt.

ISSN $1110-6131$

Vol. 24(6): 319 - 329 (2020)

www.ejabf.journals.ekb.eg

\title{
Amelioration of anxiety and locomotion during circadian rhythm change of adult zebrafish (Danio rerio) by Pranic Energy
}

\author{
Abhishek Nadig, Srikanth Nagaraja Jois*, Krishnamurthy Nagendra Prasad and \\ Vijayakumar Vinu \\ World Pranic Healing Foundation, India-Research Centre, Mysuru \\ *Corresponding Author: research@pranichealing.co.in
}

\section{ARTICLE INFO}

Article History:

Received: April 14, 2020

Accepted: Aug. 28, 2020

Online: Sept. 11, 2020

Keywords:

Prana,

Daniorerio,

Photoperiod,

Circadian rhythm,

Locomotion,

Freezing.

\begin{abstract}
Abnormal stress level, anxiety, and reduced locomotion are prominent symptoms after circadian rhythm is changed. This study investigates the influence of pranic energy on zebrafish behaviour during circadian rhythm changes. Adult zebrafish were kept in control and experimental aquariums. As an adjunct, the experimental fishes (Pranic group) received the Pranic Healing techniques for fish, food, and water to reinforce the energy in them. Individual fishes were exposed in an open area for 5 minutes and parameters including average speed, mobile speed, average acceleration, mobility rate, exploratory rate, total distance travelled, and total immobile were measured and analysed by Tox-Track tracking software. Stress was created to fishes by alternating circadian rhythm for 3 days for both groups. The changes in locomotion and anxiety data were analysed using One Way ANOVA and Mann-Whitney U test with SPSS software. Pranic treated zebrafishes (46) had increased an average speed of $8.18 \mathrm{~mm} / \mathrm{s} \quad(\mathrm{p}<.002)$, mobile speed of $7.56 \mathrm{~mm} / \mathrm{s}$ $(\mathrm{p}<.000)$, average acceleration of $323.71 \mathrm{~mm} / \mathrm{s}^{2}(\mathrm{p}<.000)$, mobility rate of $11.36 \%(\mathrm{p}<.009)$, total distance travelled of $29.490 \mathrm{~m}$ ( $\mathrm{p}<.000)$ and total immobile of $30.68 \mathrm{~s}(\mathrm{p}<.016)$ compared to control group (43).Pranic energy positively influenced the behaviour of adult zebrafish by increased locomotion and decreased anxiety levels during changed circadian rhythm.
\end{abstract}

\section{INTRODUCTION}

Energy science has been predominantly used to heal the various ailments since from the time immemorial. These include acupuncture (Madsen et al., 2009), acupressure (Cross and Charman, 2006), reiki (Kelly, 2000), qiqong (Wang et al., 1998), and Pranic Healing (Rajagopal et al., 2018) among others. Pranic Healing is an ancient science and art of healing using prana. Prana is the vital energy that keeps the plants and animals healthy and alive. Prana is also referred to as Chi, Ki or Life-force. Sui (1992) specifies that there are three major sources of prana namely solar prana, air prana, and ground prana. Water absorbs prana from sunlight, air, and ground. Plants and trees gets prana from the sun, air, water, and ground. 
Animals obtain prana from sunlight, air, water, food, and ground. Every living organism including plants, trees, and animals are surrounded by an energy field called the aura or bioplasmic body consisting of prana (Kafatos et al., 2015). According to Sui (1992) one can feel and interact with this energy. As a complementary therapy, pranic healing technique can be applied for depression (Rajagopal $\boldsymbol{e t}$ al., 2018), to improve the Lung function (Mahesh $\boldsymbol{e t}$ al., 2017), and others (Sui, 1992; 2015). Pranic healing is getting increasing scientific attention in health, biology, and in agriculture (Prasad and Jois, 2020).

Zebrafish (Danio rerio) is a tropical freshwater Teleostei, belongs to the Cyprinidae family (Sola and Gornung 2001). It is found across Southeast Asia including North-eastern India, Nepal, Bangladesh and river basins of Ganga and Brahmaputra (Bhat, 2004). The species is characterized by its smaller size measuring about $4-5 \mathrm{~cm}$, having a cylindrical body with a distinct alternating light and dark horizontal stripes (Simonetti et al., 2015). Animal models are necessary for studying the behaviour and neural responses to stress exposure (Campos et al., 2013). Among vertebrates, there has been growing interest in the use of zebrafish as a model organism in biomedical research due to rapid development. Small size of zebrafish enables large number, easy handling, high fecundity rate, high degree of genetic similarity with humans and low-cost efficiency (Gerlai, 2010). Most importantly the use of adult and larval zebrafish in stress-induced neuroscience has increased in recent decades because of its similarity of the central nervous system, physiology and genetics to humans (Kalueff et al., 2014).

Zebrafish genome shares 80-85\% homology to human gene (Howeet et al., 2013). Besides the structural homology, the brain of zebrafish is very much similar to humans and other rodents models with respect to neurochemistry (Tropepe and Sive 2003; Kalueff et al., 2013).Effect of stress and anxiety have been studied extensively by using various murine models (TeixeiraSilva et al., 2009). Recently zebrafish have emerged as a promising animal model for anxiety research due to their robust cortisol response, behavioural differences with respect to various drugs and environmental stressors (Cachat $\boldsymbol{e t}$ al., 2011). In the present study we assess zebrafish as a model of stress and anxiety by measuring how the behavioural phenotypes are affected on alteration of photoperiod. This study also aimed at investigating the impact of pranic energy after the alteration of circadian rhythm in the adult zebrafish by measuring their locomotory and freezing activity of pranic healed zebrafishes against the control group.

\section{MATERIALS AND METHODS}

\section{Specimens}

Wild type, larval zebrafish of 1 month old were procured from a breeding centre in Chennai, India. Fishes were allowed to grow till adult phase (3 months) in a well-oxygenated recirculation tank filled with dechlorinated tap water. $\mathrm{pH}$ ranged between $8.2( \pm .2)$, temperature was maintained around $28^{\circ} \mathrm{C}( \pm 0.5 \mathrm{c})$, photoperiod of 14:10 light and dark cycle, with constant filtration and half of the water, was changed every 15days. All the parameter are maintained as prescribed by OECD guidelines (1992). Zebrafish were fed twice daily with MicroPellet diet 
(Spectrum Brands Company, Germany). The diet was supplemented with Freeze-Dried Blood Worms. At most care was taken to all fishes.

\section{Study Design}

Controlled experimental design has been used in this study.

\section{Sampling}

Two identical aquaria, containing pranic group (46) and control group (43) zebra fishes were used for this study.

\section{Procedure}

The adult zebrafish were reared as described above. After acclimation in light and dark photoperiod, the fishes were exposed to three cycles of alternating light and dark periods for a total of3 days. The pranic group received pranic healing techniques from its larva stage until its adult stage. Pranic healing was provided for three days per week by a trained pranic healer. The duration of each treatment lasted for five minutes. Pranic healing techniques were also applied to aquarium water and fish food. Behavioural studies were conducted after the stress induction to measure the locomotion and freezing behaviour pattern of zebrafish. Individual fishes were exposed in an open arena, a rectangular transparent plastic trough $(50 \times 20 \times 20 \mathrm{~cm})$ for 5 minutes under the specific light condition and at constant room temperature. Locomotory and freezing activities were constantly video recorded, by a camera that was fixed $40 \mathrm{~cm}$ above the test trough and connected by the PC to start and manage the experiment video (Egan et al., 2009; Kalueff $\boldsymbol{e t}$ al., 2013). During the locomotion and freezing activities, following parameters including average speed $(\mathrm{mm} / \mathrm{s})$, average acceleration $(\mathrm{mm} / \mathrm{s})$, Mobility rate $(\%)$, total distance travelled (mm) and total time immobile (s) were measured and analysed by Tox-Track tracking software (Rodriguez et al., 2018).

\section{Data Analysis}

Data were expressed as Mean \pm SEM, for group size control (43) and Pranic (46) and significance was determined by using one was analysis of variance (ANOVA) to compare the differences between groups. For the mobility rate and total immobility, the Mann-Whitney U test was used. Difference was considered significant at $\mathrm{p}<.05$.

\section{RESULTS}

\section{Average Speed}

The average speed $(\mathrm{mm} / \mathrm{s})$ of adult zebra fish on stress-induced were measured by total distance travelled divided by total time duration which interprets the general motor function. The average speed was greater in the pranic treated condition $(34.553 \mathrm{~mm} / \mathrm{s})$ than control condition $(26.370 \mathrm{~mm} / \mathrm{s})$ (Table 1).It was found that the pranic group had $8.18 \mathrm{~mm} / \mathrm{s}$ more speed than the control group with significant difference $(\mathrm{p}<.002)$ (Figure 1A). Our findings were relevant to earlier research on behavioural impairments caused by chronic exposure of C70 nanoparticles on 
adult zebrafish were average speed shown $40 \mathrm{~mm} / \mathrm{s}$ on exposure to the novel environment for 5minutes (Sarasamma et al., 2019).

\section{Mobile Speed}

Results on stress-induced, mobile speed of adult zebra fish was greater in the pranic treated condition $(35.22 \mathrm{~mm} / \mathrm{s})$ than control condition $(27.66 \mathrm{~mm} / \mathrm{s})($ Table1).Fishes which received pranic treatment had significantly more mobile speed $(7.56 \mathrm{~mm} / \mathrm{s})$ than control group with the significant difference $(\mathrm{p}<.000)$ (Figure 1B).

Table 1: Locomotory endpoints of Control and Pranic treated Zebrafish.

\begin{tabular}{lccccccc}
\hline Variable & \multicolumn{2}{c}{ Control } & \multicolumn{2}{c}{ Pranic } & \multicolumn{1}{c}{ Df } & p \\
& Mean & SD & Mean & SD & Gain & $(\mathbf{1 , 8 7 )}$ & \\
\hline Average Speed $(\mathrm{mm} / \mathrm{s})$ & $26.37 \pm 2.20$ & 14.45 & $34.55 \pm 1.35$ & 9.17 & 8.18 & 10.302 & .002 \\
Mobile Speed $(\mathrm{mm} / \mathrm{s})$ & $27.66 \pm 1.58$ & 10.42 & $35.22 \pm 1.31$ & 8.90 & 7.56 & 13.59 & .000 \\
Average & $668.69 \pm 53.85$ & 353.11 & $992.40 \pm 49.37$ & 334.85 & 323.71 & 19.704 & .000 \\
Acceleration $\left(\mathrm{mm} / \mathrm{s}^{2}\right)$ & & & & & & & \\
Total Distance $(\mathrm{m})$ & $75.260 \pm 4.894$ & 32.093 & $104.75 \pm 29.87$ & 29.876 & 29.490 & 20.155 & .000 \\
\hline
\end{tabular}
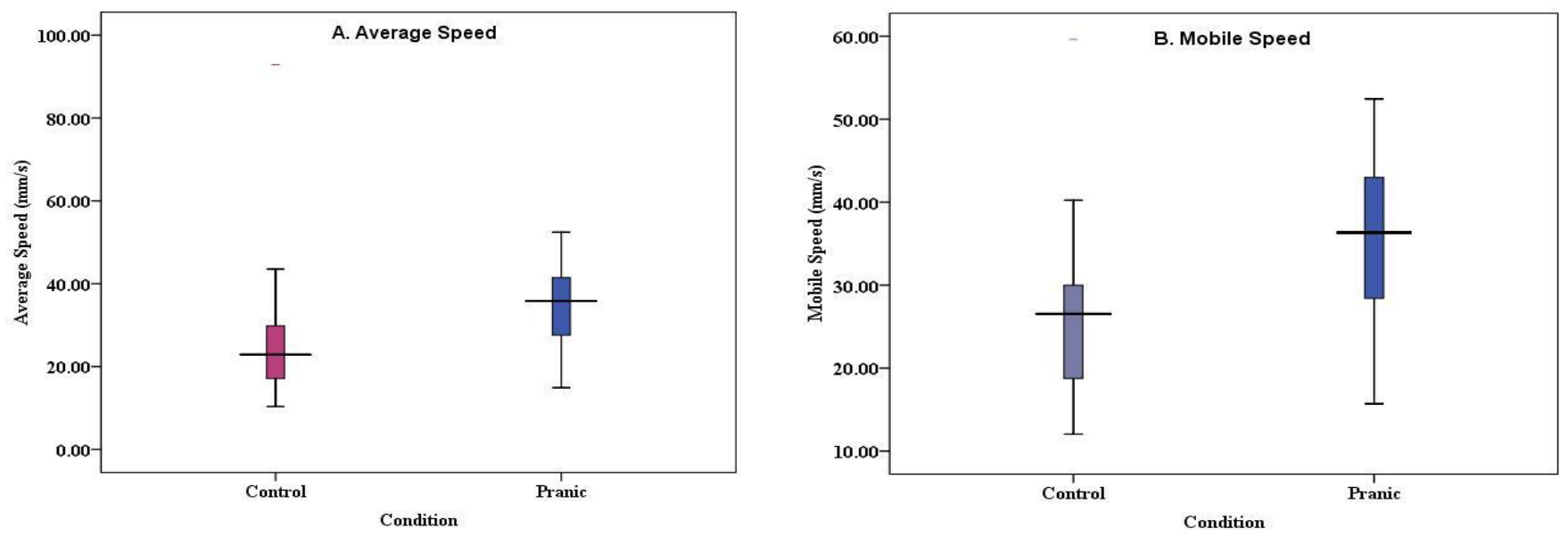

Figure 1: Behavioural Comparison of A) Average speed and B) Mobile speed between control and pranic treated zebrafish.

\section{Average Acceleration}

Acceleration is the rate of change of velocity with the time, which often indicates the state of increasing speed of zebrafish when exposed to open arena, lower value of acceleration indicates the abnormal motor and neurological function. Average Acceleration $\left(\mathrm{mm} / \mathrm{s}^{2}\right)$ of adult zebrafish on stress induced were analysed in an analysis of variance with pranic treated group (Pranic treated v/s Control) as the independent variable. The average speed was greater in the pranic $\left(992.40 \mathrm{~mm} / \mathrm{s}^{2}\right)$ than control $\left(668.69 \mathrm{~mm} / \mathrm{s}^{2}\right)$ (Table 1). It was found that pranic group had 
$\left(323.71 \mathrm{~mm} / \mathrm{s}^{2}\right)$ more acceleration than the control group and the results were significant $(\mathrm{p}<.000)$ (Figure 2A).

\section{Total Distance}

Total distance fish travelled within the novel tank which reflects the motor aspects of zebrafish swimming. Total distance travelled was also found to be higher in the pranic group (104.750 m) when compared to control group $(75.260 \mathrm{~m})$, and the results were significant $(\mathrm{p}<.000)$ (Table 1).Thus pranic treated fishes travelled more distance than the control group (Figure 2B). Our findings were relevant to (Alia and Petrunich-Rutherford, 2019) were total distance travelled of adult zebrafish on exposure to open arena was found to be $63.606 \mathrm{~m}$.
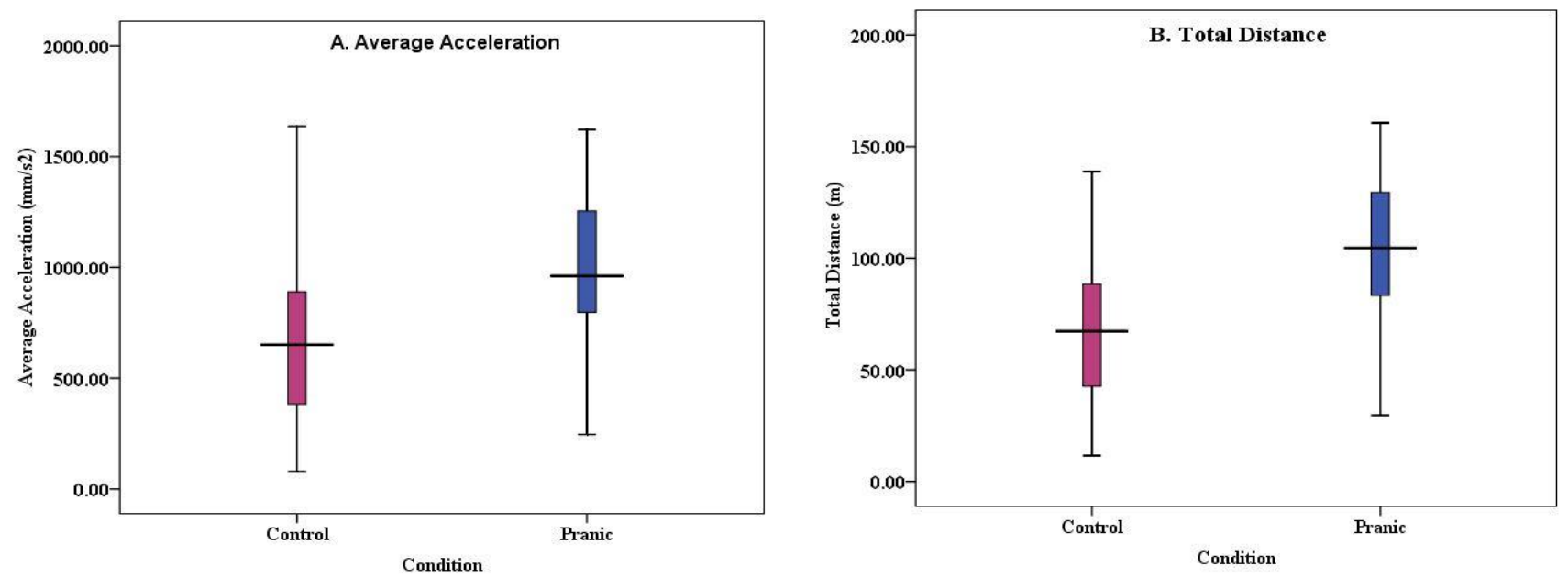

Figure 2. Behavioural Comparison of A) Average acceleration and B) Total distance between control and pranic treated Zebrafish.

\section{Mobility Rate}

Mobility rate indicates the total percentage of fish moved freely and easily when it is exposed to novel tank. The median of pranic treated zebrafish (mean rank $=51.7 \%$ ) had significantly higher rate of mobility, compared to those in the control group (mean rank $=38.29 \%),(\mathrm{U}=700.500$, $\mathrm{P}=0.009)$ (Table 2). It was clear that fishes which received pranic energy had $11.36 \%$ more mobility rate compared to the control group (Figure $3 \mathrm{~A}$ ).

\section{Total Immobility}

Immobility indicates a complete cessation of movement except gills and eyes by the fish when it is exposed to a novel tank, generally which reflects stress and anxiety. The median of control fishes (mean rank $=50.15 \mathrm{~s}$ ) had significantly more seconds of immobility, compared to those which received pranic energy (mean rank $=40.18 \mathrm{~s})(\mathrm{U}=767.500, \mathrm{P}=.0 .16)($ Table 2$)$ (Figure 3B). Similarly, earlier research work on anxiety-like behaviour responses to components of energy drinks in zebrafish was shown 40s of immobility on exposure to open arena (Alia and 
Petrunich-Rutherford, 2019). The behavioural trajectories of control and pranic treated Zebrafishes represented in Figure 4.

Table 2: Mann-Whitney U test for mobility rate and total immobility behaviour of Control and Pranic treated Zebrafish.

\begin{tabular}{cccccc}
\hline Sl.No & Variable & \multicolumn{2}{c}{ Mean Rank } & Mann-Whitney U & p \\
& & Control & Pranic & & \\
\hline 1 & Mobile Rate (\%) & 38.29 & 51.27 & 700.500 & .009 \\
2 & Total Immobility(s) & 50.15 & 40.18 & 767.500 & .016 \\
\hline
\end{tabular}
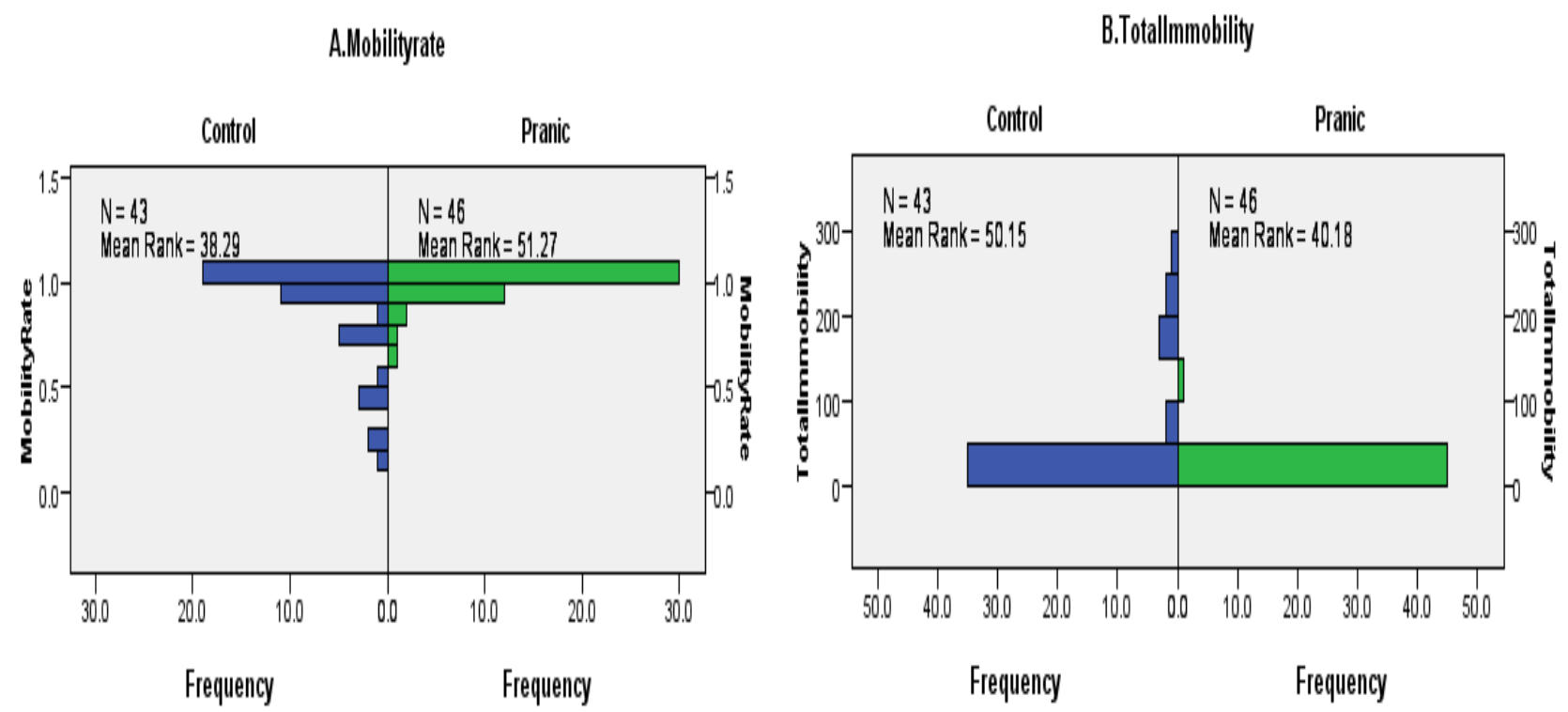

Figure 3: Behavioural Comparison of A) Mobility rate and B) Total immobility between control and pranic treated zebrafish

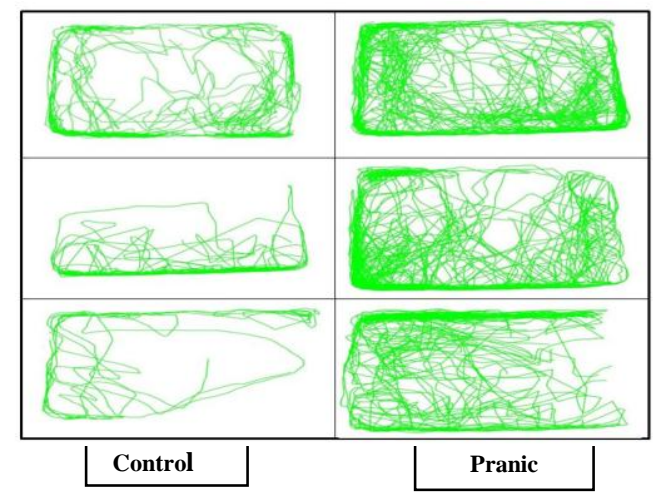

Figure 4: Behavioural trajectories of control and pranic treated Zebrafish. 


\section{DISCUSSION}

Stress is the outcome of an imbalance in the neurotransmitter level (Bhatt and

Gupta, 2013). Emotional imbalances bring imbalances in Prana (the vital energy) in the Pranamayakosha which percolates to the annamayakosha causing stress symptoms and hazards (Babu, 2009). Environmental stress both acute and chronic stress elicits the changes in the endocrine system which in turn triggers the cascade of the physiological and behavioural process this is a so-called stress response. Due to this, the gene grS357 of zebrafish with mutation of glucocorticoid receptors increases the glucocorticoid level which induces the abnormal behaviour such as decreased mobility and increased anxiety level (Ziv et al 2013 ; Stewart et al., 2012). Scientific evidence reports that adequate sleep is a biological need for life and is similar to the need for food and water to maintain healthy life (Everson et al., 1989). Earlier research on shift workers reported that lack of sleep deprivation impairs the behavioural performance by declining the neuromotorand cognitive function (Goel et al. 2009). Working for long hours without sleep showed a higher prevalence of depression and anxiety disorders (Kleppa et al., 2008). Similarly, sleep deprivation studies in rats reveals the profound changes in behavioural and physiological parameters, eventually leading to an animal's death (Everson et al., 1989; Rechtschaffen et al., 1999).

Energy healing works have the same principle as acupuncture. Similar to humans, even pets including fish have a physical body as well as the energy body. Among this, energy body serves as the template for the physical body. The state when the energy body is clear and balanced than the physical body will be healthy. Similarly when the energy body is full of congestion or depletion, then the physical body develops disease symptoms. Hence alteration of dark and light photoperiod impairs sleeping pattern of fishes, which leads to a stressful condition. This symptom appears first in the energy body and that affects the physical body in locomotion and freezing. Application of prana (vital energy) helps to prevent the disorder that manifested in the physical body and increases the life energy of the affected part of the whole body. This means the healing process gets accelerated which promotes the functional health and wellbeing. There is some evidence, suggest that energy (ATP) deficits in zebrafish larvae are related to changes in their locomotory performance (Zhang et al., 2017). The vulnerability of neurons due to their metabolic activity and energetic requirement can also result in the locomotor deficits of animals (Camilleri and Vassallo, 2014 ; Wang et al., 2018). According to (Bai et al., 2000), the application of pranic energy helps to enhances the activity of ATPase which allows more energy supply to the cells during cell growth, division and differentiation. Probably application of this pranic energy enhanced the energy level of fish which results in an increased locomotory performance of pranic treated adult zebrafishes.

Studies on Pranic energy is getting increased in Biology, health, and agriculture. Previous studies on pranic agriculture have revealed increased agricultural yield, nutritional quality, shelf life, antioxidant and polyphenol content in cucumber (Keerthika et al., 2016).Similarly, 
germination and seedling vigour test also improved significantly in the pranic treated green gram seeds when compared to control (Jois et al., 2016). Research on chronic obstructive pulmonary disease (COPD) studies, a 6 minutes walking test was conducted for COPD patients, the pranic group showed a positive trend in walking and also a tendency of improvement in Blood pressure, heart rate and respiratory rate was observed (Mahesh et al., 2017).

\section{CONCLUSION}

Pranic treated fishes had an overall increase in locomotion and freezing activity on alteration of natural photoperiod of adult zebrafish. Here, pranic energy played a very effective role in balancing the energy after the alteration of photoperiod which retains their locomotion by active swimming. The present study helps to correlate behavioural changes during alteration of natural photoperiod or those resulting from sleep deprivation during night shifts. This work opens new opportunities to study the effects of photoperiod on locomotion and anxiety performance. Their robust rest-activity cycle with diurnal lifestyle is especially helpful in studying circadian regulation of sleep in relation to diurnally active humans.

\section{REFERENCES}

Alia, A. O. and Petrunich-Rutherford, M. L. (2019). Anxiety-like behavior and whole-body cortisol responses to components of energy drinks in zebrafish (Danio rerio). Peer J, 7, e7546.

Babu, K. R. (2009). Hatha-Yoga. Health Psychology and Counselling, 71pp.

Bai, F. C.; Sun, Z.; Liu, J.; Shen, J.; Y. Shen.; Ge.R.; Bei, C.; Zhang, J.; Shi, X.; Liu, Y.; and Liu, X. (2000). Seeds induced to germinate rapidly by mentally projected qi energy are apparently genetically altered. Am. J. Chin. Med., 28: 3-8.

Bhat, A. (2004). Patterns in the distribution of freshwater fishes in rivers of Central Western Ghats, India and their associations with environmental gradients. Hydrobiologia, 529(13): 83-97.

Bhatt and Gupta, M. (2013). Study the effect of aim chanting on stress management. Intl J Creative Res Thoughts, 1(1): 1-2.

Cachat, J. M.; Canavello, P. R.; Elegante, M. F.; Bartels, B. K.; Elkhayat, S. I.; Hart, P. C.; Anna, K. T.; David, H.T.; Esther, B.; Sopan, M.; Autumn, L.L.; Stewart, A.M.; Siddharth, G.; Wong, K.; Haymore, W. and Laffoon, A. L. (2011). Modeling stress and anxiety in zebrafish. In Zebrafish models in neurobehavioral research (pp. 73-88). Humana Press, Totowa, NJ.

Camilleri, A. and Vassallo, N. (2014). The centrality of mitochondria in the pathogenesis and treatment of Parkinson's disease. CNS Neuroscience \& Therapeutics, 20(7); 591-602. 
Campos, A. C.; Fogaça, M. V.; Aguiar, D. C.; and Guimaraes, F. S. (2013). Animal models of anxiety disorders and stress. Brazilian J Psychiatry, 35; S101-S111.

Cross, J.R. and Charman, R., (2006). Healing with the Chakra Energy System: Acupressure, Bodywork, and Reflexology for Total Health. North Atlantic Books.

Egan, R. J.; Bergner, C. L.; Hart, P. C.; Cachat, J. M.; Canavello, P. R.; Elegante, M. F.; and Mohnot, S. (2009). Understanding behavioral and physiological phenotypes of stress and anxiety in zebrafish. Behav. Bain Res. 205(1); 38-44.

Everson, C. A.; Bergmann, B. M.; and Rechtschaffen, A. (1989). Sleep deprivation in the rat: III. Total sleep deprivation. Sleep, 12(1), 13-21.

Gerlai, R. (2010). High-throughput behavioural screens: the first step towards finding genes involved in vertebrate brain function using zebrafish. Molecules, 15(4); 2609-2622.

Goel, N.; Rao, H., Durmer, J. S.; and Dinges, D. F. (2009). Neurocognitive consequences of sleep deprivation. In Seminars in neurology. Thieme Medical Publishers.

Howe, K.; Clark, M. D.; Torroja, C. F.; Torrance, J.; Berthelot, C.; Muffato, M. and McLaren, S. (2013). The zebrafish reference genome sequence and its relationship to the human genome. Nature, 496(7446); 498-503.

Jois, S.N.; K.N. Prasad and K.R. Roohie. (2016). Traditional Pranic Healing Therapy for Enhanced Germination and Growth of Green Gram. In: Agriculture in Sanskrit Literature, Bhattap, K.N. (Ed.)., Rural Organization for Appropriate Development, India, ISBN: 97881-910230-1-5, pp: 337-340. 4.

Kafatos, M. C.; Chevalier, G.; Chopra, D.; Hubacher, J.; Kak, S. and Theise, N. D. (2015). Biofield science: Current physics perspectives. Glob Adv Health Med, 4 (Suppl.); 25-34..

Kalueff, A. V.; Gebhardt, M.; Stewart, A. M.; Cachat, J. M.; Brimmer, M.; Chawla, J. S.; and Gaikwad, S. (2013). Towards a comprehensive catalog of zebrafish behavior 1.0 and beyond. Zebrafish, 10(1); 70-86.

Kalueff, A. V.; Stewart, A. M.; and Gerlai, R. (2014). Zebrafish as an emerging model for studying complex brain disorders. Trends Pharmacol Sci, 35(2); 63-75.

Keerthika, T.; C.S. Devaki; F. Suma and A. Urooj, (2016). Studies on the nutritional and quality characteristics of Cucumis sativus varieties. Agric. Sci. Res. J., 6; 79-85

Kelly, M. J. (2000). Reiki and the healing Buddha. Lotus Press, New Delhi, India.

Kleppa, E.; Sanne, B.; and Tell, G. S. (2008). Working overtime is associated with anxiety and depression: the Hordaland Health Study. J. Occup. Environ. Med. 50(6); 658-666.

Madsen, M. V., Gøtzsche, P. C., and Hróbjartsson, A. (2009). Acupuncture treatment for pain: systematic review of randomised clinical trials with acupuncture, placebo acupuncture, and no acupuncture groups. British Med. J. 338; a3115. 
Mahesh PA.; Srikanth JN.; Ananthakrishna MS.; Parthasarathi G.; Chaya SK and Rajgopal R. (2017). Amelioration of quality of life and lung function of chronic obstructive Pulmonary disease by pranic healing as adjuvant therapy: a randomized double-blind placebo-controlled pilot study. Australias Med. J.10(8); 665-73.

OECD, T. N. (1992). 301: Ready Biodegradability. OECD Guidelines for the Testing of Chemicals, 301, 1-62.

Prasad, K. N. and Jois, S. N. (2020). Enhancement of Papaya (Carica papaya) Seedling Growth by Pranic Agriculture. AGRIVITA, J Agric. Sci. 42(1). 191-196.

Rajagopal, R.; Jois, S. N.; MallikarjunaMajgi, S.; Anil Kumar, M. N and Shashidhar, H. B. (2018). Amelioration of mild and moderate depression through Pranic Healing as adjuvant therapy: randomised double-blind controlled trial. Australasian Psychiatry, 26(1); 82-87.

Rechtschaffen, A.; Bergmann, B. M.; Gilliland, M. A. and Bauer, K. (1999). Effects of method, duration, and sleep stage on rebounds from sleep deprivation in the rat. Sleep, 22(1); 11-31

Rodriguez, A.; Zhang, H.; Klaminder, J.; Brodin, T.; Andersson, P. L and Andersson, M. (2018). ToxTrac: a fast and robust software for tracking organisms. Methods Ecol. Evol. 9(3); 460-464.

Sarasamma, S.; Audira, G.; Samikannu, P.; Juniardi, S.; Siregar, P.; Hao, E and Hsiao, C. D. (2019). Behavioral Impairments and Oxidative Stress in the Brain, Muscle, and Gill Caused by Chronic Exposure of C70 Nanoparticles on Adult Zebrafish. Intl J. Mol. Sci. 20(22); 5795.

Simonetti, R. B.; Marques, L. S.; Streit Jr, D. P and Oberst, E. R. (2015). Zebrafish (Danio rerio): The future of animal model in biomedical research. J. Fisheries Sci. Com, 9(3); 3945.

Sola, L and Gornung, E. (2001). Classical and molecular cytogenetics of the zebrafish, Danio rerio (Cyprinidae, Cypriniformes): an overview. Genetica, 111(1-3); 397-412.

Stewart, A.; Gaikwad, S.; Kyzar, E.; Green, J.; Roth, A. and Kalueff, A. V. (2012). Modeling anxiety using adult zebrafish: a conceptual review. Neuropharmacology, 62(1); 135-143.

Sui, C. K. (1992). The Ancient Science and Art of pranic healing, Institute of Inner studies publishing foundation India Private Ltd., India.

Sui, C. K. (2015) Pranic Psychotherapy; Institute for inner studies; Makati City.

Teixeira-Silva, F.; Antunes, F. D.; Silva, P. R. S.; Goes, T. C.; Dantas, E. C.; Santiago, M. and and de Andrade, R. M. (2009). The free-exploratory paradigm as a model of trait anxiety in rats: test-retest reliability. Physiol. Behav. 96(4-5); 729-734. 
Tropepe, V.and Sive, H. L. (2003). Can zebrafish be used as a model to study the neurodevelopmental causes of autism?. Genes, Brain and Behavior, 2(5); 268-281.

Wang, X. H.; Souders II, C. L.; Zhao, Y. H. and Martyniuk, C. J. (2018). Mitochondrial bioenergetics and locomotor activity are altered in zebrafish (Danio rerio) after exposure to the bipyridylium herbicide diquat. Toxicol. Lett. 283; 13-20.

Wang, Z.; Laidi X.; Yuanjing Y.; Chenxing M and Wenyi Z. (1998). Effect of Qigong Waiqi on platelet aggregation and the structure and function of the mitochondrion. Chinese J. Somatic Sci. 8(1); 22-25.

Zhang, J. L.; Souders II, C. L.; Denslow, N. D. and Martyniuk, C. J. (2017). Quercetin, a natural product supplement, impairs mitochondrial bioenergetics and locomotor behavior in larval zebrafish (Danio rerio). Toxicol. Applied Pharmacol. 327; 30-38.

Ziv, L.; Muto, A.; Schoonheim, P. J.; Meijsing, S. H.; Strasser, D.; Ingraham, H. A and Baier, H. (2013). An affective disorder in zebrafish with mutation of the glucocorticoid receptor. Molecular Psychiatry, 18(6); 681-691. 